\title{
USO DA MICROBIOLIZAÇÃO CONTRA Lasiodiplodia theobromae EM SEMENTES DE PINUS SPP.
}

\author{
Caciara Gonzatto Maciel1*; Marlove Fátima Brião Muniz; Jéssica Mengue Rolim²; \\ Rosa Maria Dalla Nora Michelon²; Tales Poletto²; Jéssica Emília Rabuske² \\ ${ }^{1 *}$ Universidade do Oeste de Santa Catarina, Professora do Curso de Engenharia Florestal, Xanxerê, Santa Catarina, Brasil - \\ caciaragonzatto@gmail.com \\ ${ }^{2}$ Universidade Federal de Santa Maria, Departamento de Defesa Fitossanitária, Programa de Pós-Graduação em Engenharia Florestal, Santa \\ Maria, Rio Grande do Sul, Brasil - marlovemuniz@yahoo.com.br; eng.jessicarolim@gmail.com; rosa_maria_dnm@hotmail.com; \\ tecnicotales@ hotmail.com; jessicarabuske@gmail.com
}

Recebido para publicação: 20/11/2015 - Aceito para publicação: 17/02/2017

\begin{abstract}
Resumo
O uso de agentes biocontroladores em doenças de plantas é uma alterativa aos produtos químicos que vem conquistando seu espaço, isso, devido à condição atual de proteção e manutenção do meio ambiente. Muitos organismos antagonistas apresentam potencial tanto para o controle de fitopatógenos, quanto para promover o desenvolvimento de plântulas. O presente estudo objetivou avaliar a ação antagonista de seis produtos biológicos (Trichodermil $^{\circledR}$, Trichodel ${ }^{\circledR}$, Quality ${ }^{\circledR}$, Rizos ${ }^{\circledR}$, Rizolyptus ${ }^{\circledR}$ e Nutrisolo ${ }^{\circledR}$ ) e uma cepa bacteriana (Bacillus sp.UFSM) no controle in vitro e in vivo de Lasiodiplodia theobromae patogênico a sementes de Pinus sp. Os testes in vitro foram realizados através da inibição do crescimento micelial (confronto pareado de culturas), após incubação por sete dias a $25 \pm 2{ }^{\circ} \mathrm{C}$ e fotoperíodo de 12 horas. Para os testes in vivo (desenvolvidos em condições de casa de vegetação), sementes de Pinus elliottii var. elliottii e de Pinus taeda foram inicialmente inoculadas com o patógeno e, na sequência, microbiolizadas com os agentes antagônicos, para posterior semeadura. A inoculação foi realizada através do método de contato em meio BDA por 48 horas. Todos os produtos testados apresentaram resultados positivos nos testes in vitro, em relação a testemunha. Nutrisolo ${ }^{\circledR}$, Trichodel ${ }^{\circledR}$ e Bacillus sp.-UFSM apresentaram valores superiores à testemunha para diâmetro de colo em plântulas de $P$. elliottii. Enquanto para $P$. taeda, Bacillus sp.-UFSM, Quality ${ }^{\circledR}$, Trichodel $^{\circledR}$ e Trichodermil $^{\circledR}$ alcançaram os maiores valores para essa variável. De maneira geral os agentes antagônicos atuaram promovendo as variáveis de qualidade final de mudas de Pinus taeda L. e Pinus elliottii Engelm.

Palavras-chave: Trichoderma sp.; Bacillus sp.; confronto direto; qualidade de mudas.
\end{abstract}

\begin{abstract}
Use of microbiolization against Lasiodiplodia theobromae (U.S. Pat.) Griffon \& Maublanc in Pinus spp. seeds. The use of biocontrol agents on plant disease control is an alternative to chemicals that is conquering its space, that, because of our present condition of protecting and maintaining the environment. Many organisms antagonistic might control plant pathogens and improve seedlings growing. The study aimed evaluated antagonistic action of six biologic products (Trichodermil ${ }^{\circledR}$, Trichodel ${ }^{\circledR}$, Quality ${ }^{\circledR}$, Rizos ${ }^{\circledR}$, Rizolyptus $^{\circledR}$ e Nutrisolo ${ }^{\circledR}$ ) and a bacterial strain (Bacillus sp.-UFSM) on control in vitro and in vivo of Lasiodiplodia theobromae. The in vitro tests were performed by direct confrontation method, at $25 \pm 2{ }^{\circ} \mathrm{C}$ and photoperiod of 12 hours. To in vivo tests (green house), Pinus elliottii var. elliottii and Pinus taeda seeds were inoculated with pathogen and after microbiolized with antagonist's agents, and then sown. The inoculation was performed through contact of seeds with microorganisms in BDA medium, during 48 hours. Products tested showed positive results in in vitro tests, compared to control. Nutrisolo ${ }^{\circledR}$, Trichodel ${ }^{\circledR}$ and Bacillus sp.-UFSM presented high values for stem diameter in P. elliottii seedlings. To P. taeda, Bacillus sp.UFSM, Quality ${ }^{\circledR}$, Trichodel ${ }^{\circledR}$ and Trichodermil ${ }^{\circledR}$ where highlighting. Generally, the antagonists' agents improved the variables of quality seedlings.

Keywords: Trichoderma sp.; Bacillus sp.; direct confrontation; seedlings quality.
\end{abstract}

\section{INTRODUÇÃO}

Dentre as doenças associadas ao gênero Pinus no estágio inicial de desenvolvimento de plântulas, as causadas por fungos merecem destaque, devido à agressividade e pouca especificidade dos patógenos. Lasiodiplodia theobromae (Pat.) Griffon e Maubl. (syn. Botryodiplodia theobromae Pat.) é um patógeno oportunista encontrado associado a sementes do gênero Pinus, causando redução no potencial germinativo e no desenvolvimento de plântulas, assim como podridão de sementes (MACIEL et al., 2015; CILLIERS et al., 1993). Segundo Sutherland, Diekmann; Berjak (2002), as sementes podem atuar como vetores de disseminação

FLORESTA, Curitiba, PR, v. 47, n. 1, p. 121 - 128, jan. / mar. 2017.

Maciel, C. G. et al.

ISSN eletrônico 1982-4688

DOI: $10.5380 /$ rf.v47i1.44018 
de fungos, a partir do momento em que lotes são transportados de uma região para outra, os patógenos permanecem associados ao órgão de reserva, tornando-se hábeis para disseminação.

A busca por sementes isentas de fitopatógenos é estratégica para o estabelecimento de plantios florestais (Santos et al., 2011) e a contaminação desses propágulos pode ocorrer durante o processo de coleta e armazenamento. As primeiras estratégias a serem adotadas para prevenção e controle de fungos associados a sementes são aquelas relacionadas as condições adequadas de coleta e armazenamento, seguidas do tratamento das sementes com fungicidas e agentes antagonistas. O uso de produtos biológicos apresenta-se como uma alternativa promissora, levando em consideração a atual necessidade de cuidados com o meio ambiente em que estamos inseridos. Dentre as alternativas para a redução do uso de agrotóxicos, o controle biológico é uma das mais discutidas, podendo tanto aproveitar o controle biológico natural, quanto realizar a introdução de um agente biocontrolador (BETTIOL; MORANDI, 2009). A liberação do uso de biocontroladores dentro da agricultura orgânica em 2009 foi determinante para ampliar as pesquisas e consolidar processos de registros desses agentes no Brasil (BETTIOL, 2011)

Bactérias e fungos estão envolvidos em atividades de biocontrole, sendo que o gênero Trichoderma desempenha um papel importante no controle de doenças de plantas (SABA et al., 2014). A promoção de crescimento de plantas promovida pela aplicação de Trichoderma foi inicialmente relacionada ao controle dos microrganismos prejudiciais presentes no solo (MACHADO et al., 2012). Entretanto, na ausência de fitopatógenos, segundo Lucon (2009), tal mecanismo de ação pode estar associado à produção de hormônios ou fatores de crescimento, maior eficiência no uso e absorção de nutrientes, bem como, no aumento da disponibilidade de nutrientes para planta. Testes com agentes biológicos como Trichoderma e/ou Bacillus vem se mostrando eficientes no controle de diferentes fitopatógenos como é o caso de Rhizoctonia sp. em sementes de Cedrela fissilis Vell. (LAZAROTTO et al., 2013); Botrytis cinerea Pers.:Fr em Eucalyptus benthamii Maiden et Cambage (SBRAVATTI JUNIOR et al., 2014); Cylindrocladium candelabrum Viegas em Eucalytus saligna SM. (MACIEL et al., 2012).

Diante do exposto, o objetivo deste trabalho foi avaliar a ação antagonista in vitro e in vivo dos agentes antagônicos Trichoderma spp. e Bacillus spp. no controle de Lasiodiplodia theobromae, patogênico às plântulas de Pinus elliottii e Pinus taeda, assim como sua ação na qualidade final das mudas produzidas.

\section{MATERIAL E MÉTODOS}

Os experimentos foram desenvolvidos no laboratório de Fitopatologia e na casa de vegetação pertencentes ao Departamento de Defesa Fitossanitária, localizados na Universidade Federal de Santa Maria, Santa Maria, RS, Brasil. Foram utilizados dois lotes de sementes, Pinus elliottii var elliottii e Pinus taeda L., oriundos do município de Ijuí ( $28^{\circ} 23^{\prime} 16^{\prime \prime S}$ e 5354'53"O), região noroeste do estado do Rio Grande do Sul.

Os isolados fúngicos foram obtidos a partir dos lotes de sementes utilizados nesse estudo, sua identificação morfológica, molecular e patogenicidade foi confirmada em trabalho anterior (MACIEL et al., 2015). A cepa bacteriana de Bacillus sp. utilizada no trabalho também foi obtida a partir dos lotes de semente em estudo e armazenada no Laboratório de Fitopatologia - UFSM, até sua utilização.

Ao total foram utilizados dois isolados fúngicos de Lasiodiplodia theobromae patogênicos a Pinus elliottii e P. taeda (Tabela 1) e sete agentes antagonistas (Tabela 2).

Tabela 1. Características dos isolados de Lasiodiplodia theobromae, obtidos de sementes de Pinus taeda.

Table 1. Characteristics of Lasiodiplodia theobromae isolates, from Pinus taeda seeds.

\begin{tabular}{ccc}
\hline Isolado & Origem & Código de Acesso (GenBank) \\
\hline BOT1UFSM & Sementes de P. taeda & KF924398 \\
BOT2UFSM & Sementes de P. taeda & KF924398 \\
\hline
\end{tabular}

Tabela 2. Características dos produtos biológicos e/ou isolados testados contra Lasiodiplodia theobromae.

Table 2. Characteristics of products and / or isolates tested against Lasiodiplodia theobromae.

\begin{tabular}{lllll}
\hline Tratamento & Espécie & $\begin{array}{l}\text { Concentração } \\
\text { (Céls viáveis. mL } \mathbf{~ m}^{-\mathbf{1}} \text { ) }\end{array}$ & Formulação & Empresa \\
\hline $\begin{array}{l}\text { Trichodermil } \\
\text { SC1306 }\end{array}$ & Trichoderma harzianum Rifai & $2 \times 10^{9}$ & $\begin{array}{l}\text { Suspensão } \\
\text { concentrada }\end{array}$ & $\begin{array}{l}\text { Itaforte Bio } \\
\text { Produtos }\end{array}$ \\
Quality WG & $\begin{array}{l}\text { Trichoderma asperellum } \\
\text { (Samuels, Liechfeldt et } \\
\text { Nirenberg) }\end{array}$ & $1 \times 10^{10}$ & $\begin{array}{l}\text { Grânulos } \\
\text { dispersíveis } \\
\text { em água }\end{array}$ & Grupo Farroupilha \\
\hline
\end{tabular}




\begin{tabular}{|c|c|c|c|c|}
\hline Trichodel & $\begin{array}{l}\text { Trichoderma harzianum, } \\
\text { Trichoderma viridelatroviride, } \\
\text { Trichoderma viride. Pers. }\end{array}$ & $1 \times 10^{9}$ & $\begin{array}{l}\text { Suspensão } \\
\text { concentrada }\end{array}$ & $\begin{array}{l}\text { Empresa Caxiense } \\
\text { de Controle } \\
\text { Biológico Ltda }\end{array}$ \\
\hline Rizos & Bacillus subtilis Cohn & $5 \times 10^{9}$ & $\begin{array}{l}\text { Suspensão } \\
\text { concentrada }\end{array}$ & Grupo Farroupilha \\
\hline Rizolyptus & $\begin{array}{l}\text { Bacillus subtilis (Ehrenberg) } \\
\text { Cohn }\end{array}$ & $1 \times 10^{8}$ & $\begin{array}{l}\text { Suspensão } \\
\text { concentrada }\end{array}$ & Grupo Biosoja \\
\hline ICB Nutrisolo & $\begin{array}{l}\text { Trichoderma harzianum, } \\
\text { Trichoderma asperellum, } \\
\text { Trichoderma koningiopsis } \\
\text { Samuels }\end{array}$ & $1 \times 10^{11}$ & $\begin{array}{l}\text { Suspensão } \\
\text { concentrada }\end{array}$ & ICB BIOAGRITEC \\
\hline $\begin{array}{l}\text { Obtido a partir de } \\
\text { sementes de } P \text {. } \\
\text { taeda }\end{array}$ & Bacillus sp. & - & - & - \\
\hline
\end{tabular}

\section{Ação dos biocontroladores in vitro}

A ação antagonista de Trichoderma spp. e Bacillus sp. sobre Lasiodiplodia theobromae foi avaliada através do teste de confronto direto. Para tanto, foram organizadas as seguintes combinações:

a) Trichoderma spp. x Lasiodiplodia theobromae: um cilindro de meio de cultura batata-dextrose-ágar (19 g de extrato comercial de BDA (Himedia ${ }^{\circledR}$ ) para $1000 \mathrm{~mL}$ de água) de $8 \mathrm{~mm}$ de diâmetro contendo micélio de $L$. theobromae de sete dias, foi transferido para placas de Petri $(90 \mathrm{~mm}$ de diâmetro) também contendo meio BDA, a aproximadamente $5 \mathrm{~mm}$ da borda da placa. Esse material foi incubado durante $48 \mathrm{~h}$ a $25 \pm 2{ }^{\circ} \mathrm{C}$, com fotoperíodo de 12h. Após esse período, um disco de meio de cultura BDA, com $8 \mathrm{~mm}$ de diâmetro, contendo micélio de Trichoderma spp. foi transferido para a posição oposta ao disco de micélio de L. theobromae nas placas de Petri. As placas foram incubadas durante sete dias a $25 \pm 2{ }^{\circ} \mathrm{C}$, com fotoperíodo de $12 \mathrm{~h}$. As placas-controle foram compostas apenas por Trichoderma spp. e apenas por L. theobromae. Foram feitas medidas de crescimento do diâmetro da colônia do patógeno, diariamente, com o auxílio de um paquímetro digital.

b) Bacillus sp. x Lasiodiplodia theobromae: um cilindro de meio de cultura BDA de $8 \mathrm{~mm}$ de diâmetro, contendo micélio de $L$. theobromae, foi transferido para o centro da placa de Petri ( $90 \mathrm{~mm}$ de diâmetro), também contendo meio BDA. Esse material foi incubado durante $48 \mathrm{~h}$ a $25 \pm 2{ }^{\circ} \mathrm{C}$, com fotoperíodo de $12 \mathrm{~h}$. Após esse período, quatro gotas de $10 \mu \mathrm{L}$ de suspensão bacteriana $\left(10^{8} \mathrm{ufc} \mathrm{mL}^{-1}\right)$ foram dispostas equidistantes entre si e do centro da placa de Petri, uma gota em cada quadrante. As placas foram mantidas em incubadora, nas mesmas condições. As avaliações foram baseadas em medidas diárias do crescimento do diâmetro da colônia do patógeno, com o auxílio de um paquímetro digital, e verificação da formação de halo de inibição, metodologia adaptada de Sottero et al. (2006).

A partir dos dados de crescimento micelial (mm), calculou-se a porcentagem de inibição do crescimento micelial, segundo Menten et al. (1976), com a fórmula: \% inibição = [(crtest - crtrat) /crtest $]$ x 100, em que crtest $=$ crescimento radial da testemunha; e crtrat $=$ crescimento radial do tratamento.

O delineamento experimental utilizado foi inteiramente casualizado, com oito tratamentos e cinco repetições, em que cada repetição é composta por uma placa de Petri. Inicialmente, foi verificado se os dados apresentavam distribuição normal pelo teste de Shapiro-Wilk, utilizando o software BioEstat 5.0. Os dados que não seguiram a distribuição normal foram transformados segundo $\sqrt{ }(x+0,5)$, para a análise da variância. Os resultados em unidades decimais não sofreram transformaçães. A comparação das médias foi feita pelo teste LSD a 5\% de probabilidade utilizando-se o software SISVAR 5.3.

\section{Ação dos biocontroladores in vivo}

Para a composição dos tratamentos do teste in vivo selecionou-se os cinco produtos/isolados com potencial antagonista em relação à testemunha (Tabela 3). As sementes utilizadas nos testes permaneceram armazenadas no freezer $\left(3-5^{\circ} \mathrm{C}\right)$ por duas semanas até a sua utilização, como método de superação da dormência (BRASIL, 2009). Antes da aplicação dos agentes biocontroladores, as sementes passaram por uma assepsia superficial. Utilizou-se uma solução de álcool $70 \%\left(\mathrm{v} \mathrm{v}^{-1}\right)$ por $30 \mathrm{seg}$, em seguida hipoclorito de sódio $1 \%\left(\mathrm{v} \mathrm{v}^{-1}\right)$ por 1 min e, na sequência, três banhos em água destilada e esterilizada e, então, foram deixadas secar sobre 
papel-filtro esterilizado, dentro de câmara de fluxo laminar. As sementes foram inoculadas com Lasiodiplodia theobromae (Bot2), esse isolado foi escolhido pois quando confrontado com os antagonistas (in vitro), apresentou resultados de controle superiores. As sementes permaneceram em contato com a cultura fúngica por 48 horas (incubação a $25 \pm 2{ }^{\circ} \mathrm{C}$, fotoperíodo de $12 \mathrm{~h}$ ), na sequência passaram pelo mesmo processo para inoculação do agente antagônico. Os tratamentos testemunhas receberam apenas a inoculação de L. theobromae.

Após a aplicação dos tratamentos, as sementes foram semeadas em bandejas $(45 \times 28 \times 13 \mathrm{~cm})$, divididas em quatro repetições de 25 sementes por tratamento, totalizando 100 sementes. O substrato utilizado foi Carolina Soil ${ }^{\circledR}$ (previamente esterilizado em autoclave $\left[120^{\circ} \mathrm{C}\right.$ e $\left.1 \mathrm{~atm}\right]$ por dois tempos de $60 \mathrm{~min}$, com intervalo de $24 \mathrm{~h}$ ). O material foi mantido em casa de vegetação com temperatura entre 22 e $26^{\circ} \mathrm{C}$ e com irrigação diária através de um sistema de microtubos, cada tratamento recebeu $400 \mathrm{~mL}$ de água por dia, sendo esta quantidade dividida em quatro irrigações de $50 \mathrm{~mL}$.

As avaliações efetuadas foram: a) emergência: semanais (até os 60 dias), computando-se o número de plântulas emergidas, resultados expressos em porcentagem. Na última contagem de emergência (60 dias), realizaram-se as seguintes avaliações: b) diâmetro do colo, comprimento da parte aérea, radicular e comprimento total: mediram-se 10 plântulas por repetição. Estas foram medidas com o auxílio de paquímetro digital; c) massa verde de plântulas: todas as plântulas de cada repetição foram pesadas em balança analítica de precisão 0,01 g.; e d) massa seca de plântulas: para a determinação da massa seca, as plântulas utilizadas na determinação da massa verde foram acondicionadas em sacos de papel e colocadas em estufa a $60 \pm 3{ }^{\circ} \mathrm{C}$ até atingirem massa constante.

O delineamento experimental utilizado foi completamente casualizado, com quatro repetições para cada teste realizado. Inicialmente, verificou-se se os dados apresentavam distribuição normal pelo teste de ShapiroWilk, no Programa BioEstat 5.0. Para a análise da variância, os dados que não seguiram a distribuição normal foram transformados segundo $\sqrt{ }(\mathrm{x}+0,5)$. Os resultados em unidades decimais não sofreram transformações. A comparação das médias foi feita pelo teste de LSD a 5\% de probabilidade, com o software SISVAR 5.3.

\section{RESULTADOS}

A utilização dos agentes antagônicos reduziu o crescimento micelial dos dois isolados do patógeno, diferindo estatisticamente da testemunha (Tabela 3). Para o isolado Bot1, o produto Nutrisolo ${ }^{\circledR}$ à base de Trichoderma sp. apresentou os resultados mais promissores $(49,73 \mathrm{~cm})$, seguido do Trichodel ${ }^{\circledR}(54,01 \mathrm{~cm})$, Bacillus sp. UFSM $(57,55 \mathrm{~cm})$ e Quality ${ }^{\circledR}(59,09 \mathrm{~cm})$. Nos tratamentos em que o patógeno foi confrontado com as cepas bacterianas (Rizolyptus ${ }^{\circledR}$, Rizos ${ }^{\circledR}$ e Bacillus sp.-UFSM) foi possível observar a formação de um halo de inibição (Figura 1D), interrompendo o crescimento do patógeno.

Quando confrontado com o isolado Bot2 os melhores resultados foram encontrados com Trichodel ${ }^{\circledR}$, seguido do Nutrisolo ${ }^{\circledR}$ e Trichodermil ${ }^{\circledR}$. Os produtos Rizos ${ }^{\circledR}$ e Rizolyptus ${ }^{\circledR}$ à base de Bacillus sp., não diferiram estatisticamente da testemunha (Tabela 3).

Tabela 3. Crescimento micelial e porcentagem de inibição de Lasiodiplodia theobromae em cultivo pareado com Trichoderma spp. e Bacillus sp., in vitro, após cinco dias de incubação $\left(25 \pm 2{ }^{\circ} \mathrm{C}\right.$ - fotoperíodo de 12h).

Table 3. Growth mycelial and inhibition of percentage mycelial of Lasiodiplodia theobromae in paired culture with Trichoderma spp. and Bacillus sp., in vitro, five days after de incubation $\left(25 \pm 2^{\circ} \mathrm{C}-\right.$ photoperiod of $12 \mathrm{~h}$ ).

\begin{tabular}{lcccc}
\hline & \multicolumn{2}{c}{ Crescimento micelial $(\mathbf{c m})$} & \multicolumn{2}{c}{ \% de inibição } \\
\hline Tratamento & L. theobromae (Bot1) & L. theobromae (Bot2) & L. theobromae (Bot1) & L. theobromae (Bot2) \\
\hline Trichodermil $^{\circledR}$ & $68,29 \mathrm{~d}^{*}$ & $54,69 \mathrm{abc}$ & $14,63 \mathrm{~d}$ & $31,63 \mathrm{abc}$ \\
Quality $^{\circledR}$ & $59,09 \mathrm{c}$ & $61,17 \mathrm{c}$ & $26,13 \mathrm{c}$ & $23,53 \mathrm{c}$ \\
Trichodel $^{\circledR}$ & $54,01 \mathrm{~b}$ & $42,25 \mathrm{a}$ & $32,48 \mathrm{~b}$ & $43,43 \mathrm{a}$ \\
Nutrisolo $^{\circledR}$ & $49,73 \mathrm{a}$ & $50,20 \mathrm{ab}$ & $37,83 \mathrm{a}$ & $37,24 \mathrm{ab}$ \\
Rizolyptus $^{\circledR}$ & $73,4 \mathrm{e}$ & $73,5 \mathrm{~d}$ & $8,15 \mathrm{e}$ & $8,12 \mathrm{~d}$ \\
Rizos $^{\circledR}$ & $71,15 \mathrm{de}$ & $71,5 \mathrm{~d}$ & $11,31 \mathrm{de}$ & $10,31 \mathrm{~d}$ \\
Bacillus sp.-UFSM $_{\text {Testemunha }}$ & $56,55 \mathrm{bc}$ & $57,55 \mathrm{bc}$ & $28,00 \mathrm{bc}$ & $28,06 \mathrm{bc}$ \\
\hline C.V. (\%) & $80 \mathrm{f}$ & $80 \mathrm{~d}$ & $0,0 \mathrm{f}$ & $0,0 \mathrm{~d}$ \\
\hline *Médias seguidas pela mesma letra, na coluna, não diferem entre si pelo teste de LSD a 5\% de significância. C.V: coeficiente de variação.
\end{tabular}



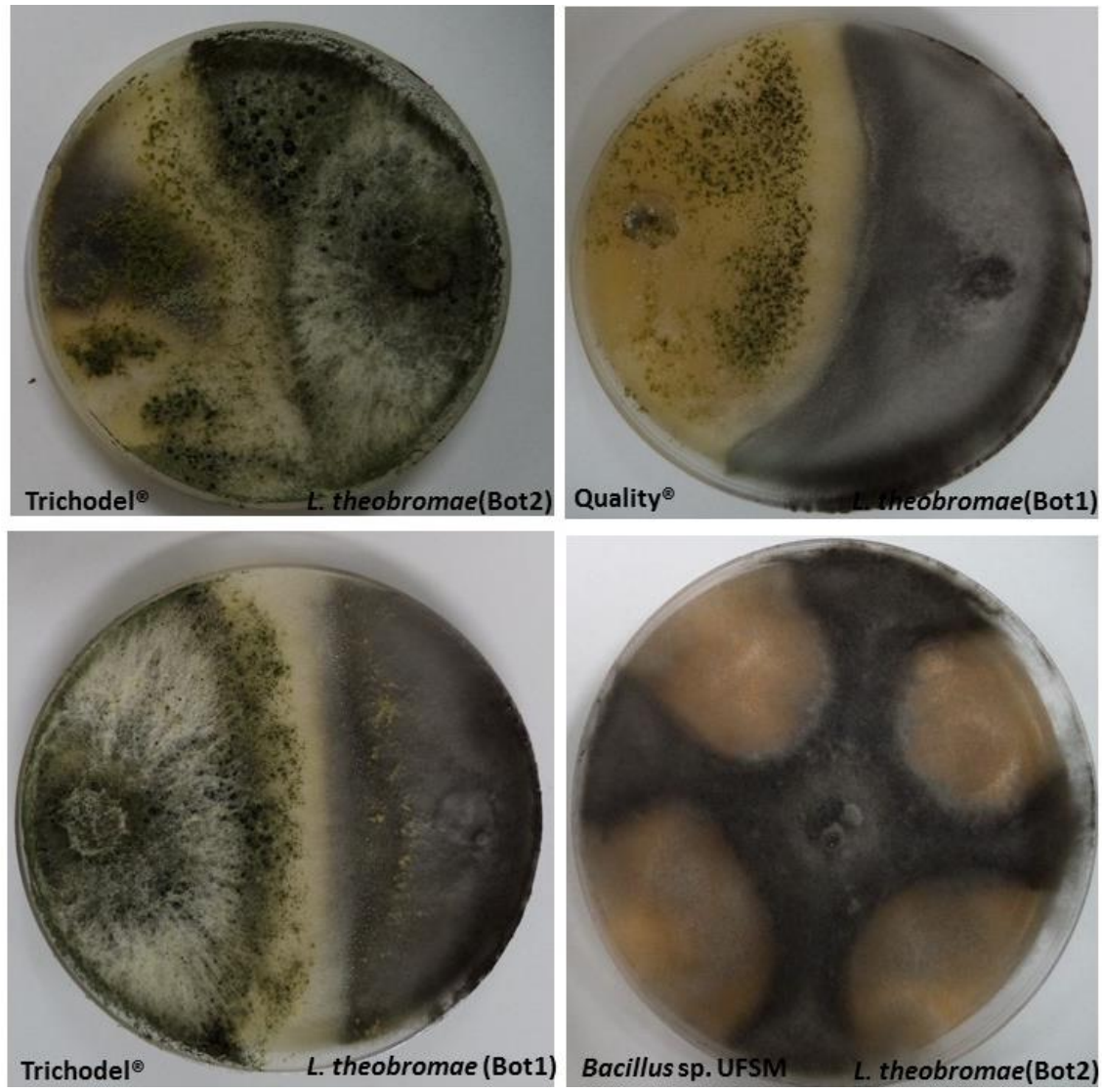

Figura 1. Confronto direto dos agentes antagonistas com Lasiodiplodia theobromae.

Figure 1. Direct confrontation of antagonists with Lasiodiplodia theobromae.

Na tabela 4 são apresentados os resultados referentes a qualidade final de mudas de Pinus elliottii produzidas aos 60 dias, após o tratamento das sementes com os agentes antagônicos. O tratamento das sementes com Trichodermil ${ }^{\circledR}$ conferiu maiores valores numéricos para a variável emergência de plântulas, alcançando $77 \%$, entretanto este diferiu apenas do tratamento com Nutrisolo ${ }^{\circledR}(48 \%)$. Para a variável diâmetro do colo os tratamentos com Nutrisolo ${ }^{\circledR}$, Trichodel ${ }^{\circledR}$ e Bacillus sp.-UFSM apresentaram resultados promissores, diferindo estatisticamente da testemunha.

Tabela 4. Efeito do biocontrole na qualidade final de mudas de Pinus elliottii var elliottii, através das variáveis: emergência (E), diâmetro do colo (DC), comprimento de parte aérea (PA), comprimento de parte radicular (PR), massa verde (MV) e massa seca (MS).

Table 4. Effect of biocontrol in the final quality of seedlings of Pinus elliottii var elliottii, through the variables: emergency (E), stem diameter (DC), shoot length (PA), root length (PR), fresh matter (MF) and dry matter (MS).

\begin{tabular}{lcllccc}
\hline \multirow{2}{*}{ Tratamentos } & \multicolumn{5}{c}{ Variáveis } \\
\cline { 2 - 7 } & $\mathbf{E ~}(\boldsymbol{\%})$ & DC $(\mathbf{c m})$ & PA $(\mathbf{c m})$ & PR $(\mathbf{c m})$ & MV $(\mathbf{g})$ & MS $(\mathbf{g})$ \\
\hline Trichodel $^{\circledR}$ & $62 \mathrm{ab}$ & $1,3 \mathrm{ab}$ & $10,33 \mathrm{~ns}$ & $14,64 \mathrm{~ns}$ & $6,00 \mathrm{~ns}$ & $2,47 \mathrm{~ns}$ \\
Trichodermil $^{\circledR}$ & $77 \mathrm{a}$ & $1,24 \mathrm{abc}$ & 9,84 & 13,57 & 6,81 & 2,60 \\
Quality $^{\circledR}$ & $58 \mathrm{ab}$ & $1,18 \mathrm{bc}$ & 8,83 & 11,57 & 4,59 & 2,09 \\
Nutrisolo $^{\circledR}$ & $48 \mathrm{~b}$ & $1,33 \mathrm{a}$ & 9,81 & 12,93 & 4,94 & 2,20 \\
Bacillus $_{\text {sp.-UFSM }}$ & $71 \mathrm{ab}$ & $1,24 \mathrm{ab}$ & 10,43 & 15,44 & 7,63 & 2,85 \\
Testemunha & $68 \mathrm{ab}$ & $1,10 \mathrm{c}$ & 9,90 & 13,18 & 6,61 & 2,54 \\
\hline C.V $(\%)$ & 30,39 & 7,6 & 16,1 & 29,5 & 39,1 & 22,3 \\
\hline
\end{tabular}

*Médias seguidas pela mesma letra, na coluna, não diferem entre si pelo teste LSD a 5\% de significância. ${ }^{\text {ns }}$ Não significativo pelo teste LSD a 5\% de significância. C.V: coeficiente de variação.

FLOREST A, Curitiba, PR, v. 47, n. 1, p. 121 - 128, jan. / mar. 2017.

Maciel, C. G. et al.

ISSN eletrônico 1982-4688

DOI: $10.5380 /$ rf.v47i1.44018 
O percentual de emergência para plântulas de Pinus taeda, não diferiu aos 60 dias, variando entre 5068\% (Tabela 5). Para a variável diâmetro do colo, o tratamento das sementes com Bacillus sp.-UFSM apresentou o maior valor $(1,09 \mathrm{~cm})$, seguida do Quality ${ }^{\circledR}(1,00 \mathrm{~cm})$, Trichodel $^{\circledR}(0,98 \mathrm{~cm})$ e Trichodermil $^{\circledR}(0,97 \mathrm{~cm})$. Resultados superiores com o produto Quality ${ }^{\circledR}$ foram verificados no comprimento de parte aérea, alcançando $9,23 \mathrm{~cm}$, entretanto não diferindo estatisticamente da testemunha $(8,52 \mathrm{~cm})$. Para outras variáveis como comprimento de parte radicular, massa verde e massa seca observou-se resultados numericamente superiores com a utilização dos biocontroladores, porém não houve diferença significativa. Dessa maneira percebe-se que a aplicação desses agentes antagonistas confere melhores condições ao substrato e desenvolvimento da muda, e testes com tempo de exposição superior a 60 dias podem ser realizados, para que a diferença em relação a testemunha, que não recebeu os agentes, possa ser visualizada estatisticamente.

Tabela 5. Efeito do biocontrole na qualidade final de mudas de Pinus taeda, através das variáveis: emergência (E), diâmetro do colo (DC), comprimento de parte aérea (PA), comprimento de parte radicular (PR), massa verde (MV) e massa seca (MS).

Table 5. Effect of biocontrol in the final quality of seedlings of Pinus taeda, through the variables: emergency (E), stem diameter (DC), shoot length (PA), root length (PR), fresh matter (MF) and dry matter (MS).

\begin{tabular}{lllcrcc}
\hline \multirow{2}{*}{ Tratamentos } & \multicolumn{7}{c}{ Variáveis } \\
\cline { 2 - 7 } & $\mathbf{E ~ ( \% )}$ & DC $(\mathbf{c m})$ & PA $(\mathbf{c m})$ & PR $(\mathbf{c m})$ & MV $(\mathbf{g})$ & MS $(\mathbf{g})$ \\
\hline Trichodel $^{\circledR}$ & $50^{\mathrm{ns}}$ & $0,98 \mathrm{abc}$ & $7,07 \mathrm{c}$ & $9,78^{\text {ns }}$ & $3,10^{\text {ns }}$ & $1,71^{\text {ns }}$ \\
Trichodermil $^{\circledR}$ & 68 & $0,97 \mathrm{abc}$ & $8,09 \mathrm{bc}$ & 11,26 & 4,21 & 2,04 \\
Quality $^{\circledR}$ & 60 & $1,00 \mathrm{ab}$ & $9,23 \mathrm{a}$ & 11,67 & 3,74 & 1,97 \\
Nutrisolo $^{\circledR}$ & 64 & $0,89 \mathrm{bc}$ & $7,62 \mathrm{bc}$ & 9,04 & 3,38 & 1,80 \\
Bacillus $_{\text {sp.-UFSM }}$ & 65 & $1,09 \mathrm{a}$ & $7,62 \mathrm{bc}$ & 12,09 & 3,47 & 1,82 \\
Testemunha & 62 & $0,86 \mathrm{c}$ & $8,52 \mathrm{ab}$ & 8,93 & 3,36 & 1,84 \\
\hline C.V $(\%)$ & 34,75 & 8,96 & 10,18 & 29,71 & 26,54 & 13,74
\end{tabular}

*Médias seguidas pela mesma letra, na coluna, não diferem entre si pelo teste LSD a 5\% de significância. ${ }^{\text {ns }}$ Não significativo pelo teste LSD a $5 \%$ de significância. C.V: coeficiente de variação.

\section{DISCUSSÃO}

Testes in vitro, comparando a eficiência do Trichoderma e fungicidas no controle de L. theobromae foram realizados por Bhadra et al. (2014), os autores encontraram percentual de inibição entre 60-80\% para as cepas utilizadas e consideram a utilização de Trichoderma promissora e com efeitos menos agressivos ao meio ambiente que os produtos químicos. De doze cepas de Trichoderma testadas in vitro para o controle de $L$. theobromae, patogênica à Annona squamosa L., três apresentaram alta atividade de biocontrole (KUNZ, 2007), dessa maneira torna-se importante a realização de bioensaios in vivo, visto que algumas condições de temperatura e umidade podem interferir no desenvolvimento tanto do agente de biocontrole, quanto do patógeno. De acordo com Lorito et al. (2010) a variedade e o número de compostos encontrados no metaboloma de espécies de Trichoderma são surpreendentemente altos e incluem enzimas líticas e hormônios, além de muitos metabólitos secundários com importantes funções biológicas. No presente trabalho foi possível observar e quantificar a ação dos biocontroladores in vitro, sobre o patógeno Lasiodiplodia theobromae.

$\mathrm{Na}$ Índia, foi testado o efeito de dezessete cepas bacterianas no controle in vitro de Lasiodiplodia theobromae, patogênico a Hevea brasiliensis L., destas, sete apresentaram potencial antagonista, sendo seis delas pertencentes ao gênero Bacillus (SAJITHA; FLORENCE; DEV, 2014). Resultados semelhantes foram apresentados por Zhang et al. (2014), que apostaram no controle biológico para diminuir a alta aplicação de fungicidas no controle de Lasiodiplodia sp. que causa danos na madeira de álamo, os autores ressaltaram a eficiência da B37 - Bacillus subtilis no controle in vitro do patógeno.

A necessidade de substituir e/ou reduzir a utilização de produtos químicos, faz com que outros estudos nessa mesma linha de pesquisa ampliem seu espaço. Lasiodiplodia theobromae foi verificado causando podridão em Manihot esculenta Crantz na Tailândia, estudo de estratégias de controle, apontaram a utilização de controle biológico como uma alternativa promissora, foram testados 15 isolados de Trichoderma spp., e comprovada sua ação in vitro e in vivo (BUENSANTEAI; DUSIT ATHINUWAT, 2012).

O uso de agentes antagonistas para o tratamento de substrato, favoreceu o desenvolvimento de plântulas de Gochnatia polymorpha (Less.) Cabr (MACHADO et al., 2015) e Pinus taeda (BRUNETTA et al., 2010). No presente trabalho percebeu-se o efeito promissor dos biocontroladores na qualidade final das mudas de $P$. taeda e $P$. elliottii, sendo uma alternativa para os viveiristas. 


\section{CONCLUSÕES}

- Os agentes de controle biológico à base de Trichoderma spp. e Bacillus spp. mostraram-se eficientes no controle in vitro de Lasiodiplodia theobromae.

- Os agentes antagônicos atuaram ampliando as variáveis de qualidade final de mudas de Pinus taeda e Pinus elliottii, não interferindo significativamente na emergência de plântulas.

\section{AGRADECIMENTOS}

A Coordenação de Aperfeiçoamento de Pessoal de nível Superior (CAPES) pelo incentivo financeiro através da bolsa de doutorado concedida; e ao Conselho Nacional de Desenvolvimento Científico e Tecnológico (CNPq), através do projeto número 473722 / 2013 - 5.

\section{REFERÊNCIAS}

BHADRA, M.; KHAIR, A.; HOSSAIN, A.; SIKDER, M. Efficacy of Trichoderma spp. and fungicides against Lasiodiplodia theobromae. Bangladesh Journal of Scientific and Industrial Research, Bangladesh, v. 49, n. 2, p. 125-130, 2014.

BETTIOL, W. Biopesticida use and research in Brazil. Outlooks and Pest Management, Essex, p. 280-283, 2011.

BETTIOL, W.; MORANDI, M. A. B. Biocontrole de doenças de plantas: uso e perspectivas. Jaguariúna: Embrapa Meio Ambiente, 2009. 341 p.

BRASIL. Ministério da Agricultura, Pecuária e Abastecimento. Regra para análise de sementes. Brasília, DF. 395 p. 2009.

BRUNETTA, J. M. F. C.; ALFENAS, A. C.; MAFIA, R. G.; GOMES, J. M.; BINOTI, D. B.; FONSECA, N. A. N. Isolamento e seleção de rizobactérias promotoras do crescimento de Pinus taeda. Revista Árvore, Viçosa, v. 34, n. 3, p. 399-406, 2010.

BUENSANTEAI, N.; ATHINUWAT, D. The antagonistic activity of Trichoderma virens strain TvSUT10 against cassava stem rot in Thailand. African Journal of Biotechnology, Bowie, v. 11, n. 84, p. 14996-15001, 2012.

CILLIERS A. J.; SWART W. J.; WINGFIELD M. J. A review of Lasiodiplodia theobromae with particular reference to its occurrence on coniferous seeds. South African Forestry Journal, Pretoria, n. 166, p. 47-52, 1993.

KUNZ, R. Control of Post Harvest Disease (Botryodiplodia sp.) of Rambutan and Annona Species by Using a Bio-Control Agent (Trichoderma sp.). Experiments were undertaken by the Industrial Technology Institute (ITI) in cooperation with the International Centre for Underutilised Crops (ICUC).p. 1-44. África. 2007.

LAZAROTTO, M.; MUNIZ, M. F. B.; BELTRAME, R.; SANTOS, A. F. dos; MÜLlER, J.; ARAÚJO, M. M. Tratamentos biológico e químico em sementes de Cedrela fissilis para controle de Rhizoctonia sp. Cerne, Lavras, v. 19, n. 1, p. 169-175, 2013.

LORITO, M.; WOO, S. L.; HARMAN, G. E.; MONTE, E. Translational Research on Trichoderma: From'Omics to the Field. Annual Reviws Phytopathology, v. 48, p. 395-417. 2010.

LUCON, C. M. M. Promoção de crescimento de plantas com o uso de Trichoderma spp. Infobibos, Informações Tecnológicas. Disponível em: < http://www.infobibos.com/Artigos/2009_1/trichoderma/index.htm > 2009 (Acesso em 03.11.2015).

MACHADO, D. F. M.; TAVARES, A. P.; LOPES, S. J.; SILVA, A. C. F. da. Trichoderma spp. in emergence and growth of cambará seedlings (Gochnatia polymorpha (Less.) Cabrera). Revista Árvore, Viçosa, v. 39, n. 1, p. 167-176, 2015.

MACHADO, D. F. M.; PARZIANELLO, F. R.; SILVA, A. C. F.; ANTONIOLLI, Z. I. Trichoderma no Brasil o fungo e o bioagente. Revista de Ciências Agrárias, Lisboa, v. 35, n. 1, p. 274-288. 2012.

MACIEL, C. G.; LAZAROTTO, M.; MEZZOMO, R.; POLETTO. I.; MUNIZ, M. F. B.; LIPPERT, D. B. Trichoderma spp. no biocontrole de Cylindrocladium candelabrum em mudas de Eucalyptus saligna. Revista Árvore, Viçosa, v. 36, n. 5, p. 825-832, 2012. 
MACIEL, C. G.; MUNIZ, M. F. B.; MEZZOMO, R.; REINIGER, L. R. S. Lasiodiplodia theobromae associated with seeds of Pinus spp. originated from the northwest of Rio Grande do Sul, Brazil. Scientia Forestalis, Piracicaba, v.43, n.107, p. 639-646, 2015. <Disponível em: http://www.ipef.br/publicacoes/scientia/leitura.asp? Article $=15 \&$ Number $=107 \& \mathrm{p}=\mathrm{n}>$

MENTEN, J. O. M.; MACHADO, C. C.; MUNISSI, E.; CASTRO, C.; KIMATI, H. Efeito de alguns fungicidas no crescimento micelial de Macrophomina phaseolina (Tass) Goid. "in vitro".Fitopatologia Brasileira, Brasilia, v. 1, p. 57-66, 1976.

SABA, H. Trichoderma - a promising plant growth stimulator and biocontrol agente. Mycosphere, Guiyang, v. 3, n. 4, p. 524-531, 2014.

SAJITHA, K. L.; FLORENCE, E. J. M.; DEV, S. A. Screening of bacterial biocontrols against sapstain fungus (Lasiodiplodia theobromae Pat.) of rubberwood (Hevea brasiliensis Muell.Arg.). Research in Microbiology, Paris, v. 165, p. 541-548, 2014.

SANTOS, A. F. dos; PARISI, J. J. D.; MENTEN, J. O. M. Patologia de sementes florestais. Colombo: Embrapa Florestas, 2011. 236 p.

SBRAVATTI JÚNIOR, J. A.; AUER, C. G.; PIMENTEL, I. C.; SANTOS, A. F. dos; SCHULTZ, B. Seleção in vitro de fungos endofíticos para o controle biológico de Botrytis cinerea em Eucalyptus benthamii. Floresta, Curitiba, v. 43, n. 1, p. 145-152, 2013.

SOTTERO A. N.; FREITAS, S. dos S.; MELO, A. M. T. de; TRANI P. E. Rizobactérias e alface: colonização rizosférica, promoção de crescimento e controle biológico. Revista Brasileira de Ciência do Solo, Viçosa, v. 30, n. 2, p. 225-234, 2006.

SUTHERLAND, J. R.; DIEKMANN, M.; BERJAK, P. Forest Tree Seed Health. IPGRI Technical Bulletin No. 6. International Plant Genetic Resources Institute, Rome, Italy. 2002.

ZHANG, X.; ZHAO, G.; LI, D.; LI, S.; HONG, Q. Identification and Evaluation of Strain B37 of Bacillus subtilis Antagonistic to Sapstain Fungi on Poplar Wood. The Scientific World Journal, New York, v. 2014, p. $1-10,2014$. 